\title{
Assessing The Impact Of Sediments On Best Management Practices (Bmps) For Highway Runoff Control At Wolaita Sodo Town
}

\author{
Dagimwork Asele Manuka* \\ *Lecturer, Department of Civil Engineering, College of Engineering, Wolaita Sodo University, Wolaita Sodo, Ethiopia \\ *Corresponding Author Email address: dagimworka@gmail.com
}

\begin{abstract}
The goals of this work are to estimate the amount of erosion and to evaluate the impacts of sediments on Best Management Practices (BMPs) for highway runoff and also used to estimate the annual erosion and sediment yield from the construction sites considering various erosion control management methods that might be used in the sites. Once the sediment yield is found, a model was designed to estimate the sediment capture efficiency of different Best Management Practices (BMPs) and to evaluate the service year of each BMP before it is filled with sediment. The two major objectives of this project are: to predict sediment yield from highway construction sites under different erosion management conditions and secondly to estimate the service year of sediment control BMPs treating runoff from highway construction sites. The BMPs selected for evaluation were: detention ponds, infiltration trenches, grass lined swales, grass lined swales with rock check dams, and bio retention areas. Each respective BMP requires different measures of efficiency to accurately assess its effectiveness and service year.
\end{abstract}

Keywords: Best management practices, Efficiency, Erosion, , Highway runoff, Sediment

\section{INTRODUCTION}

Erosion is the detachment of a portion of the soil profile or soil surface. This can occur by either the impact of raindrops, or by the shear forces of water flowing across the soil surface. Soil particles can be transported over a short distance (such as the splash from a raindrop impact), or a longer distance (to the bottom of the slope, or into a water conveyance) before being deposited. The transportation and deposition process are called sedimentation. Erosion and sedimentation are natural processes. These processes occur daily, on all land, as the result of wind, and water. However, the effect of natural erosion is usually only noticeable on a geologic time scale. Disturbance of the soil surface, including activities like construction, farming, or logging, greatly increases the amount of sediment loss from the site due to erosion. Sediments that escape the site may eventually enter a stream or wetland, and changes the characteristics of a water body (Fifield, J., 2010). These changes may result in physical hindrances to navigation or increased flood risks. Sedimentation in wetlands can alter the hydrology or destroy hydric vegetation. Sedimentation that occurs in streams can cover up habitat that certain integral parts of the food web rely on. Sediment may also smother nesting sites for fish or amphibians, or cover mussel beds that filter significant quantities of pollutants from water that ultimately becomes our drinking water (Navya et al.,2013).

According to (Scienjo, K., 2015)The average erosion from a designated area over a designated time may be computed by using the Revised Universal Soil Loss Equation (RUSLE). RUSLE is an erosion model developed by the U. S. Department of Agriculture to provide decision support in soil conservation planning. It is a set of mathematical equations used to determine what conservation practices might be applied to a landscape to reduce or limit the amount of erosion and sediment loss. The original 
application for RUSLE was agriculture, primarily cropland production. Subsequent revisions have widened the program's applicability to be useful to other land-disturbing activities like mining, forest management, and construction sites (Price J.C., and Karesh.R, 2000). During rainy season most highways which are found around highly elevated areas are affected with sediments which come from different place with the form of soil erosion. This has its negative impacts on the highway and those impacts have other respective impacts on the peoples which are using those highways. Erosion is a natural phenomenon that occurs when soils and sediments are moved by wind, glacial motion, water flow, and raindrop impact. Rain on the ground surface causes two types of erosion, inter-rill and rill. "Inter-rill erosion is the movement of soil by rain splash and its transport by this surface flow. Rill erosion is erosion by concentrated flow in small rivulets" (Scienjo, 2015.)

The sediment eroded may carry additional pollutant load from the hillside abutting the highway. Pollutants could be nitrogen, phosphorus, carbon, or other roadway pollutants that wash off of the hillside. It is important to treat the soil and pollutant load prior to entering a water body.

This treatment process prevents pollutants from getting into water bodies and adversely affecting plants and wildlife. For storm water runoff, treatment is generally accomplished through implementation of best management practices, BMPs. The Clean Water Act (CWA) was established to "restore and maintain the chemical, physical, and biological integrity of the Nation's waters," through processes that reduce the pollutant loads within the water bodies (EPA.Water, (June 1, 2014)). The Clean Water Act mandates the application of BMPs on construction sites larger than one acre and requires a National Pollutant Discharge Elimination System (NPDES) permit. Under Section 404, highway sites fall into infrastructure development, and must be following the CWA. BMP effectiveness is at the heart of this report; however, descriptions of the BMP characteristics or processes that reduce pollutants are provided to augment explanations of BMP success or failure in specific situations and to provide the reader with a better understanding of the appropriate applications or limitations of the BMP. Rarely are only qualitative or observational results given from a reference. Where they are used in this synthesis, they were extracted from research studies that included data, and the lack of data supporting the observation is noted. Some reports (especially those by agencies in state departments of highway or transportation) included comments or observations by motor-grader operators or other equipment operators on BMP effectiveness. We did not include these observations because they are subjective and lack measured data or any other type of quantified BMP information to support them. We are not suggesting such observations have no merit, but because they are not otherwise scientifically supportable, they have been excluded. Along this same line, we emphasize that this synthesis does not simply describe or summarize BMPs that are used on or are applicable to roads (e.g., from state BMP manuals), because our intent was to avoid implying that broad acceptance and implementation of a BMP guarantee effectiveness or that its performance is well supported by research (kell., 1938).

\subsection{Statement of the problem}

Wolaita Sodo is a town which is found in higher elevation besides that the town is below Damota Mountain. This makes the town directly exposed to soil erosion, sedimentation and flooding due to this the town has been affecting by sedimentation effect and floods at rainy season. This flooding and sedimentation effects has negative impacts on different perspectives among those perspectives the first and immediate action needier is the effects of sediments on highway by the reason of erosion. Now the time is rainy season at most Ethiopian areas, Wolaita Sodo is one of those areas which has high rain amount. At this time the sediment effect on highway at Wolaita Sodo is high and easily visible. At this time when we see the edges of the highways in the town, they are covered with sediments and this makes 
the roads no comfortable for the users especially for the pedestrian and vehicles due to these accidents are happening.

The main reasons for the accidents occurring in the town are primarily the pedestrian are using the vehicles road to walk by finding out the convenient part for walk because the shoulders and side edges of the roads are accumulated with sediments. Secondly the eroded soil particles and sediment particles are now accumulated on the asphalt and coble stone roads due to these accumulated materials the accidents are happening by sliding and other factors. Those all reasons make us to select Wolaita Sodo town as our study area on the title of effects of sediments on Best Management Practices (BMPs) for highway runoff control.

\section{RELATED WORK}

Soil erosion is the detachment, entrainment, and transport of soil particles from their place of origin by the agents of erosion, such as water, wind, and gravity. It is a form of land degradation and can be categorized as either geological or accelerated surface soil erosion. The latter is a result from human activities that expose the soil surface and thus enabling erosive agents such as rain to wash away topsoil (Paterson, W.D.O., 1987).

Dislodged soil particles are often stored within depressions in the land but may be dislodged during storm events. The amount of silt or sediment delivered into water systems through the processes of entrainment, transportation, and deposition is a function of changes in surface drainage patterns, terrain roughness, vegetation, and climatic conditions. Water is the most significant agent of soil erosion. The removal of vegetative cover and the breakdown of soil structure through compaction and loss of organic matter often reduce infiltration and accelerate runoff and the entrainment of soil particles. The amount and sizes of soil particles transported as sediment increase as the volume and velocity of runoff increase. Hence, on project sites under development, drainage control is pre-requisite to erosion control (EPA, 2014).

Sedimentation is the build-up (aggradations) of sediment on the land surface or the bed of a watercourse. Sedimentation in drainage systems and in rivers leads to the raising of bed levels resulting in flash floods during heavy rainstorms. It is a dynamic process and is dependent upon the geomorphic and hydraulic characteristics of the drainage system. The deposited sediment tends to remain in place for short periods of time, the next rain flushing the sediment downstream. Thus, sediment tends to be transported in pulses depending on the flow characteristics of the drainage systems. Suspended sediment is empirically one of the best indicators of sediment delivery into the drainage system or watercourse from the land during land clearance and earthwork activities (Douglass, Swift and Burns,1974).

It can be used to indicate the relative magnitude of soil loss from a project site. The following sections outline various types of erosion processes.

\section{a) Rain splash Erosion}

The force of falling raindrops can dislodge soil particles, which are then available for entrainment by slope runoff.

\section{b) Sheet Erosion}

Sheet erosion occurs when loose or detached soil is transported downhill in a uniform layer, with no discernible concentrated flow. The shallow layer of flowing water rolls many particles downslope, but fine particles may be carried in suspension. Sheet erosion occurs rapidly during heavy rain but is readily interrupted by vegetation. Where surface irregularities break the laminar sheet wash, turbulence may cause incision and the initiation of rill formation. The amount of soil loss depends on the depth and 
velocity of flow, soil structure, and terrain. A serious consequence of sheet erosion is the very noticeable subsoil layer that is exposed at the surface after the topsoil is removed. Vegetation is particularly hard to re- establish in such layers.

\section{c) Rill Erosion}

Entrainment of soil particles over an exposed terrain causes rill formations. Rills are shallow channels usually no more than $30 \mathrm{~cm}$ deep but can be meters long. They may be widespread on compacted exposed surfaces, which are devoid of vegetation. Water flows more quickly in a rill because it is concentrated and this increases the detachment and transportation of soil particles. Vegetation plays an important role in dissipating runoff velocity and encourages deposition onsite.

\section{d) Gully Erosion}

Gullies are incised channels, which often began as rills. The headwall of a gully tends to cut back upslope and the sidewalls retreat through slumping associated with subsurface water altering the stability of the gully sides, or undercutting by surface water flowing over the head or sides of the gully. Gullies are highly effective conveyors of sediment to rivers and their density and depth are indicators of the severity of erosion.

\section{e) Riverbank Erosion}

Rivers constantly adjust the shape of their channels and erode their banks under natural conditions. Much of the sediment carried by rivers in a natural rainforest state is derived from bank erosion. However, changes in runoff and sediment loads alter the stability of river channels and rapid bank erosion may occur as a consequence.

\section{f) Tunnel Erosion}

Tunnel erosion frequently occurs in areas where the texture of the overburden or weathered rock and soil changes. Water moving readily through coarser materials may not be able to infiltrate into underlying finer layer and thus moves downslope. Such water tends to converge and develop a subsurface natural pipe, which can enlarge as fine particles are carried away.

Eventually the pipe may enlarge into a tunnel whose roof may collapse leaving a hole, which develops into a surface gully. Increased infiltration accelerates tunnel erosion and gully development by tunnel collapse.

\section{g) Wind Erosion}

Wind erosion occurs on dry surfaces, particularly where loose fine material is abundant. Although not usually a problem in Malaysia, it may be a nuisance where bare ground on construction sites dries out yielding dust, which is blown onto neighbouring premises. The majority of dust generated and emitted is related to earth moving demolition, construction traffic on unpaved surfaces, and wind over disturbed compacted soil (Fifield, 2010.)

\subsection{Drainage Control/ Runoff Management}

Rates of soil erosion are often greatest where runoff water becomes concentrated along drainage lines and stream. Erosion control measures in these locations can have a major effect in reducing the risk of downstream sedimentation (White, P and Hunt, D, 2001).

- The principles to be followed in establishing a drainage system in development sites are to direct runoff water so that it does not run across disturbed and unstable areas.

- Locate and study the hydraulic characteristics of the drainage system which include: - overall drainage pattern - dimensions and flow of any rivers and streams - springs and wells including flow and well logs - 
subsurface conditions including aquifer type and capacity, depth to water table, and location of perched water table - natural drainage depressions, basins, and sinks - floodplains, both on-site and downstream, that will undergo change due to grading and development.

- Construct drainage routes and channels in such a way that the beds do not degrade and contribute to the sedimentation problems.

- Remove the sediment load accumulated in channels during the dry season to avoid downstream sedimentation.

- For hillside areas, slope drains must be constructed or extended as work progresses. Such drains include berm drains, cascading drains, and sumps at the toes of the cascading drains to reduce the velocity. Diversion banks may be necessary to intercept runoff from higher areas and to divert it away from exposed areas. The longitudinal slope of the bank must not be excessive or the bank itself will erode.

- In granular soil areas, a diversion drain may serve the same purpose as a diversion bank, but is more effective if it is lined with a geo fabric material to resist erosion of the drain.

- For unsealed roads, culverts and cross drains must be constructed where the road intercepts a stream depression or natural drainage channels. The practice has been to direct the runoff from the table drains into the upstream end of the culverts. To reduce erosion, it is better to locate table drain culverts $20-30$ $\mathrm{m}$ from the watercourse so that it provides a natural filter for the runoff before it enters the stream.

- Temporary interceptor ditches and berms with filters at inlets should be constructed to direct runoff from the development area into any sediment basin.

- The drainage and deviation of natural watercourses, including provisions of bunds and culvert shall be carried out wherever appropriate.

- No watercourse or the reserve along the watercourse shall be disturbed until full plan details of the proposed works have been submitted to and approved by the DID. A system shall be maintained such that existing downstream water quality with respect to total sediment load is maintained, or improved if so directed by the authorities concerned. The authorities concerned shall approve any sediment traps that is provided with the drainage works.

- The authorities concerned may require permanent drains to have sediment traps of adequate capacity and other conservation measures. The sediment traps shall have the capacity to hold no less than $10 \mathrm{~cm}$ of silt and sediment at any time. Material removed from the traps shall not be placed in such a way that it becomes a source of sedimentation of storm water drains downstream.

- Drains that are not mechanically stabilized shall be grassed and maintained.

- Ineffective drainage should be noted (especially during wet weather) and promptly corrected.

Runoff management is a process to control the direction, volume and velocity of the transport medium and safely convey storm water so that its potential for erosion is reduced. They help to direct storm water away from exposed soils. Transport control should direct the flow to areas where the sediment can be trapped and removed (Fifield, 2004.). The four $\mathrm{D}^{\text {ee }} \mathrm{S}$ of Transport Control is:

$\checkmark$ Decrease the amount of runoff

$\checkmark$ Detain runoff to reduce its velocity

$\checkmark$ Divert runoff from erodible areas

$\checkmark$ Dissipate the flow of runoff

\subsection{Sediment Impacts on Best Management Practices (BMPs)}

It is assumed that all of the soil eroded from the site is transported into a Best Management Practices (BMPs) prior to flowing into a water body. The intent of the BMPs is to determine the service year of the BMPs based on its sediment-trapping efficiency, which depends on variable site conditions and BMPs 
design. The conditions that dictate efficiency differ by BMPs and should all be easily accessible for an engineer to attain. The model should give users the quantity of soil deposited in the BMPs on an annual basis and the estimated service year of the BMPs in question. This program should be used as a tool to adjust BMPs designs to meet their required performance and service year. Users should also be able to compare construction site management options and different types of BMPs using this program to assist them in determining what fits the site best. Users will first input the sediment delivery as tons/acre/year from the construction site, which will be converted into tons/year to the BMP. The user will input soil type, watershed area, BMPs volume, and how full the BMPs will be before cleanout or reconstruction is required. Not all of the input variables are applicable to every BMP (ERA., 2013).

\subsection{Best Management Practices BMP Selection}

BMPs are often required to treat storm water runoff from highway construction sites. The BMPs that are used for this application are used primarily to capture sediment, and they must be suitable to roadside applications (e.g., relatively small footprints). The BMPs selected to be modeled and evaluated were detention ponds, infiltration trenches, grass-lined swales, grass lined swales with check dams, and bio retention areas.

\subsubsection{Detention Pond}

Detention ponds (Figure 1) are very common BMPs in municipal storm water management systems. Detention ponds work by temporarily storing storm water runoff within the basin. The water should be detained for up to 72 hours, allowing time for sediment particles to settle to the bottom of the basin. There is an outlet works system to allow water to slowly be released into natural channels, which helps reduce peak flow. The trapping efficiency range is between 50 and $90 \%$, based on past studies conducted on detention ponds. Detention ponds are especially effective when the construction site is open and lacks slope stabilization since it can handle large volumes of runoff, and it can remove large amounts of sediment; however, detention ponds are still very effective after the site has been stabilized with permanent cover.

The detention pond is also relatively easy to manage and clean out as needed throughout the construction project. Ponds are generally utilized for larger sites, because they can treat significant amounts of runoff.

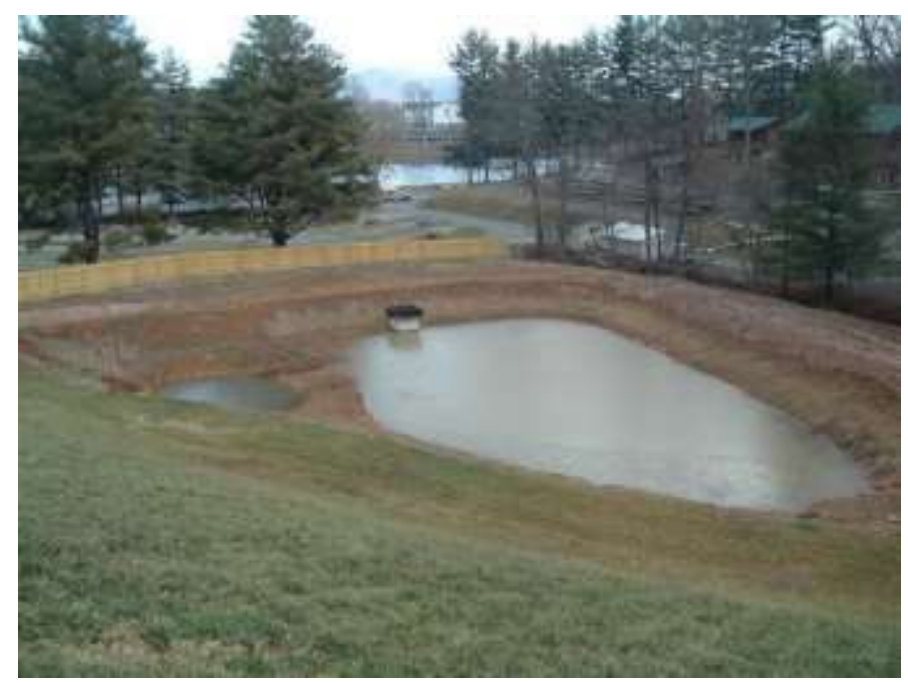

Figure 1: Detention pond (Storm water Management)

\subsubsection{Infiltration Trench}


Infiltration trenches (Figure 2.) work similarly to detention ponds, as they also detain water within the system. The porous media within the infiltration trench is used to help filter the sediment out of storm water runoff. There is no outlet system within infiltration trenches, because the intent of this BMP is to allow runoff to infiltrate into the groundwater table. The trapping efficiency range of infiltration trenches is $60-90 \%$ based on past studies of infiltration trenches. They are not as useful on large sites, or sites with bare soil. The total volume of the BMP is already $60 \%$ filled with gravel (leaving $40 \%$ of the total volume as empty pore spaces within the gravel bed) before any storm water enters the system.

This means that the capacity of infiltration trenches is a lot lower than that of a detention pond with the same footprint. Once a site has been stabilized, infiltration trenches could be a viable option, because they allow the storm water to naturally infiltrate into the ground, with all the sediment and pollutant load remaining in the trench.

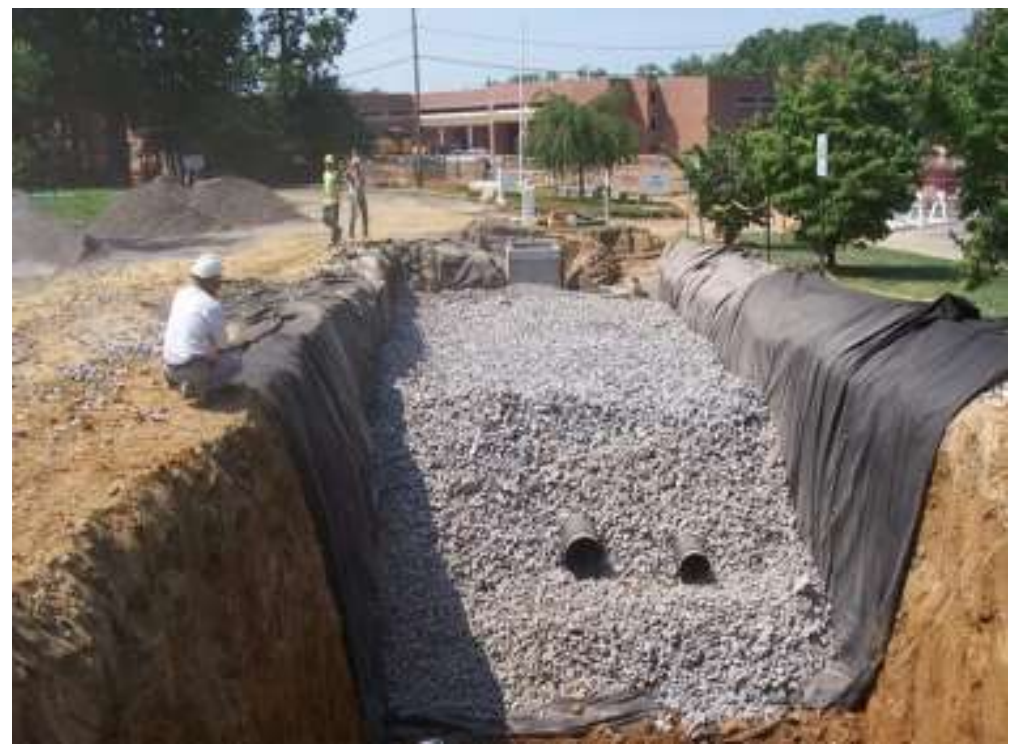

\subsubsection{Grass Lined Swale}

Figure 2: Infiltration Trench

Grass lined swales (Figure 3) target pollutants by reducing the flow velocity of storm water runoff using filter media, in this case vegetation. As the flow velocity of runoff is reduced, the time runoff is in the system increases, allowing pollutant loads more time to settle to the bottom of the swale. The removal efficiency range of grassed swales is $65-99 \%$ based on recent studies of grassed swales. These post construction BMPs do not take up much space. As with infiltration trenches swales will fill up with sediments. if they are downstream of a construction site with bare soil Therefore, they may be better applied as a post-construction BMP. 


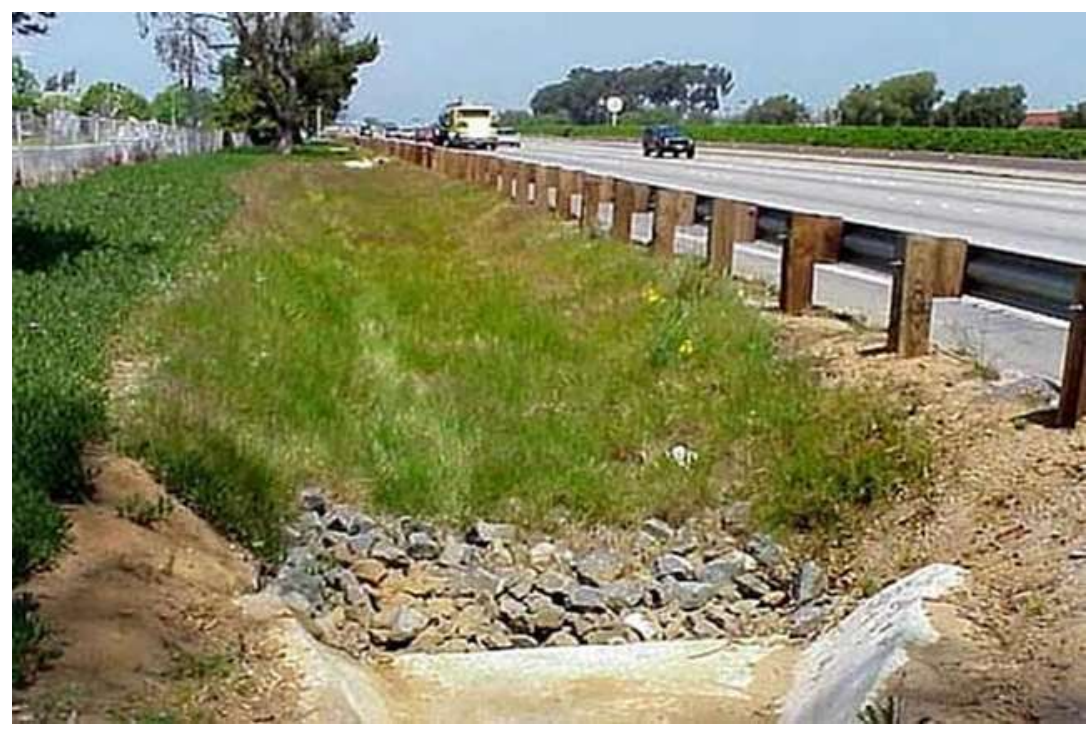

Figure 3: Grass lined swale Bio infiltration Swales

\subsubsection{Grass Lined Swale with Rock Check Dam}

Grass lined swales with check dams (Figure 4) are similar to grassed swales, with the storm water runoff being slowed as it passes through the vegetation. With the check dams in place, there will be some ponding within the system as well, which slows the runoff further, allowing even more time for the sediment to settle out of the flow. The removal efficiency range of grassed swales with rock check dams is $20-98 \%$ based on past studies on these systems.

Previous research also states that grassed swales are more efficient with check dams present.

Grassed swales with check dams are post construction BMPs that are ideal for small footprints. Since the goal of swales with check dams is to slow the flow of runoff, they do not have a large capacity, making them less effective for construction sites with bare soil.

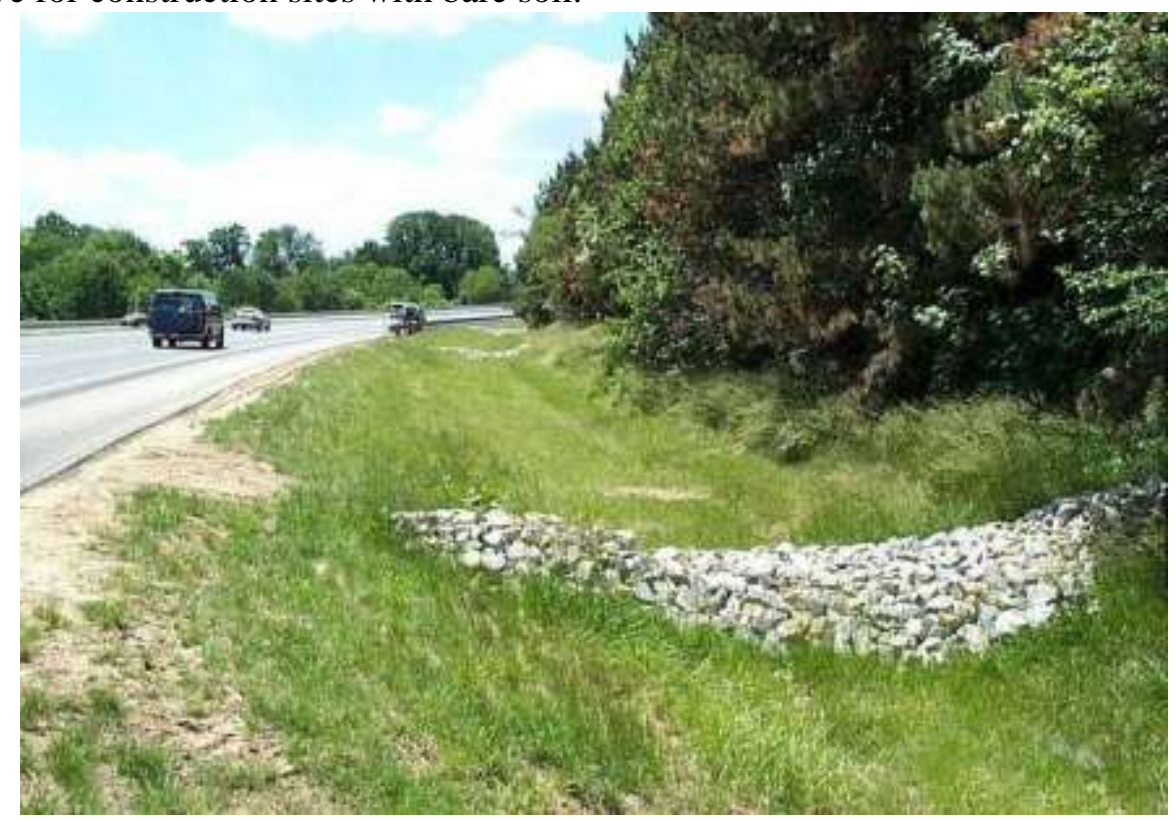

Figure 4: Grass lined swale with rock check dam 


\subsubsection{Bio retention Area}

Bio retention areas, or rain gardens, (Figure 5) treat storm water runoff by temporarily storing runoff within the depression created for rain gardens. The storm water should be able to infiltrate, and will also be directed to an outlet works into a channel. As the water is temporarily detained, the peak flow should be reduced in streams and creeks prior to the treated storm water entering receiving streams. According to previous studies on bio retention gardens, the trapping efficiency range is 29-99\%. Rain gardens are great BMPs for high visibility areas that still require storm water BMP. These rain gardens are highly recommended to be used as post construction management systems, due to the amount of landscape design and cost that is input to construct an effective and pleasing garden.

These areas treat small to medium sized runoff areas, with a recommendation of treating less than 10 acres of runoff area.

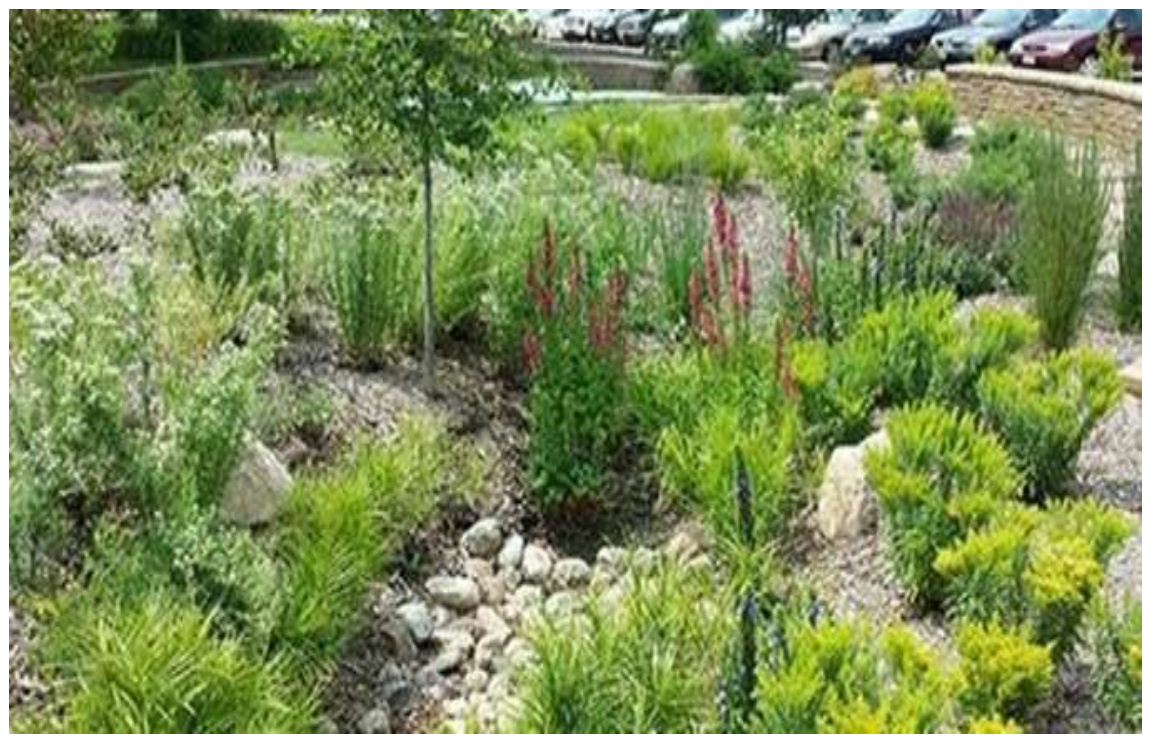

Figure 5: Bio retention Garden

\section{MATERIALS AND METHODS}

An understanding of Wolaita Sodo people requires a historical journey back into their history. Historical analysis helps us to understand the nature of the indigenous institutions, how these institutions shaped their production systems and the general landscape This study covers three thematic areas namely Golla, Aroge Arada and Keera Sefer. Wolaita Sodo city is one of the cities found in Ethiopia and it is the capital city of Wolaita people. Wolaita Sodo is a town and separate woreda in south-central Ethiopia. The administrative center of the Wolaita Zone of the Southern Nations, Nationalities, and Peoples Region, it has a latitude and longitude of $6^{\circ} 54^{\prime} \mathrm{N} 37^{\circ} 45^{\prime} \mathrm{E}$ with an elevation between 1,600 and 2,100 meters $(5,200$ and 6,900 feet) above sea level. It was part of the former Sodo woreda which included Sodo Zuria which completely surrounds it (Paulo's, 2007)

\subsection{Thematic Area}

Our Thematic area of this thesis is Golla, Aroge Arada and Keera Sefer. This is because the whole town is not being affected by the sedimentation problem and studying the whole town is not possible at this level that work have selected those three specific areas which are highly affected by erosion and sedimentation. 


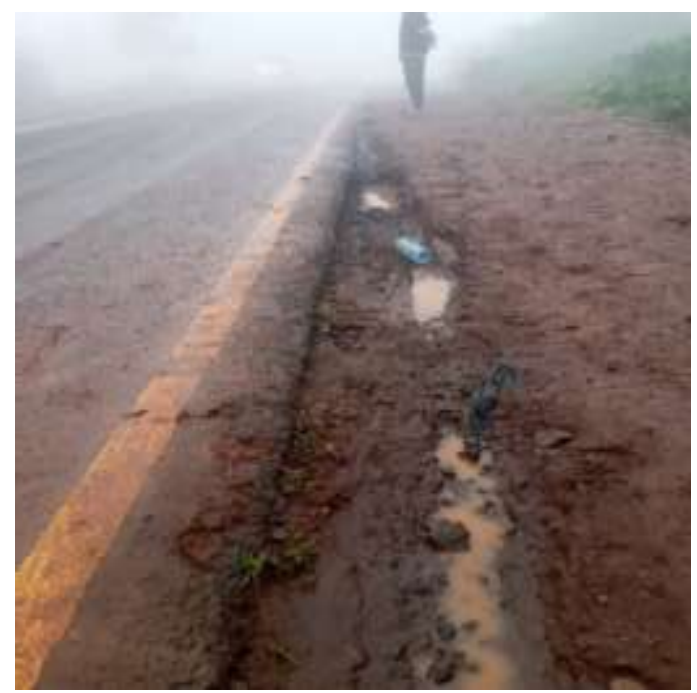

a) Soil erosion

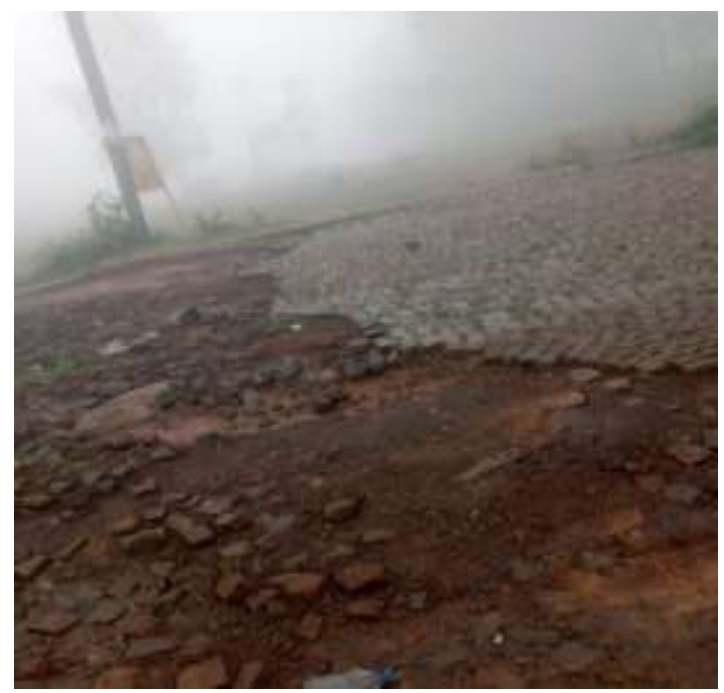

b) Flooding effect

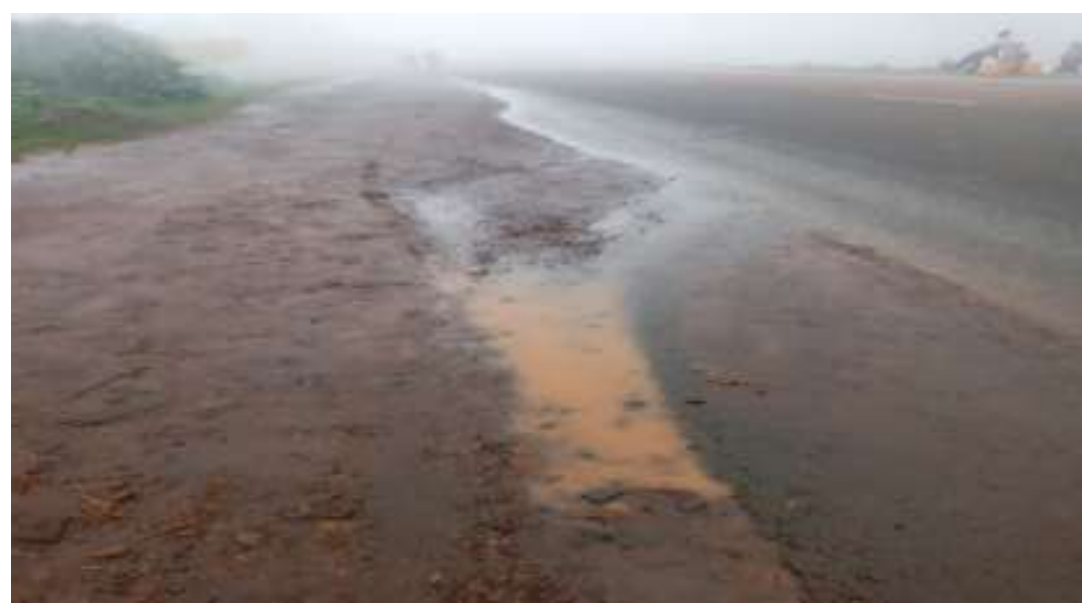

c) Sedimentation effect

Figure 6: Effects of sediment and erosion on highway

\subsection{Sample size determination}

In the study we have thematic area of Golla, Aroge Arada and Keera Sefer data collection method are visualization and interviews. Visualization method is the methods of looking the effects of sediments on Best Management Practices for highway runoff control by using our naked eyes. During this time of visualization, the study, there are specified focused areas that are highly affected by these effects of sediments, flooding and soil erosion and the second sample the study used are 40 peoples and there are 20 questionnaires. one person has asked four different questions and one question has been asked eight times and then according to the answer of those questions the study results will be obtained and also, we will include different organizations in these questionnaires like Wolaita soda town municipality and water 
supply and sewage treatment offices and there is the hope that the answers gotten from those organizations will be reliable.

Individual interviews were carried out with a nonrandom sample of 40 peoples randomly. Key socioeconomic questions were administered to get an overview. Observation was an integral part of the entire thesis. The collected qualitative data were then entered into the computer, thereafter, information on similar issues was found with the help of a word processor by creating further patterns and categorization of the text. This thesis is the result of such a process. The formal interviews with the 40 peoples randomly were summarized and were included in relevant sections to support the qualitative information in addition to the secondary data sources.

\subsection{Sample procedure}

The procedures the study followed is first visual inspection is the key thing to determine the organizations which have jobs related with this study and also to determine that what kind of questionnaires are going to be asked. Then preparing the questionnaires which are required for interview purpose. And finally starting making interviews consisting of twenty different questionnaires for forty persons and one person will be asked only eight questions that means each question has eight different answers and finally to get the results the answer must be put in percentage and the study can simply has the result and at the end putting the result that what kind of measures should be taken.

\section{RESULTS AND ANALYSIS}

Most of the resources presented are available through public organizations and individual interviews the organizations that the study focused are Wolaita Sodo town municipality and Wolaita Sodo town water supply and sewage treatment offices. Through the course of this study, it has been found that erosion is a largely variable event. If a site is well constructed or established with good ground cover and a stable soil there will be minimal annual erosion. When a site is on poor soil, with minimal ground cover and is poorly designed, the opportunity for soil erosion increases significantly. Sediment Control Best Management Practices (BMPs) are installed to treat the soil erosion, whether large or small quantities of soil are moved.

The function and longevity of sediment control Best Management Practices (BMPs) depend upon many site-specific conditions and can vary significantly from location to location. Engineers should use good site design and management practices to reduce erosion and extend the life of the BMP on site. The Best Management Practices (BMPs) model developed in this study does not account for temporal variability in efficiency. As a BMP becomes filled with sediment, the efficiency is reduced. Modelling the temporal 
change in efficiency is a complex process, which was not evaluated in this project, but could be investigated in future work.

It depends upon a hypothetical storm sequence that is based historical data. While the hypothetical storm sequence reflects average rain, data collected over many years, it is an estimation. With the climatic changes that have occurred in recent years, there may be some variance with this storm sequence. The cover and soil are assumed to be uniform and constant across the entire site.

Due to this simplification, the soils and cover may not perfectly match an entire site. The Best Management Practices (BMPs) model uses generic soil types, not specific soils that can be found in soils surveys and maps. This is another simplification that may create some discrepancy between the lifespan estimation and the actual lifespan of the BMP.

BMPs themselves have erosion occurring within them from the sidewalls of basins and from vegetative cover dying, decomposing and turning into soil. No internal erosion or soil production from vegetation was accounted for within the BMP model because the amounts of soil produced from these avenues is not very well known. The efficiency of the BMPs was found using past studies of BMPs, and may not be valid for site-specific conditions. These efficiency functions would benefit from further study.

\section{CONCLUSION}

Based on other work performances, the results that were found for bare cut sites up to long-term stabilization on sites seems reasonable. The most erosion occurs when a site does not have permanent ground cover, which is where Best Management Practices (BMPs) are most needed. The BMP that is selected for the construction portion of a project must be chosen knowing that there will be significant quantities of sediment moving in that period. The BMP utilized while a site is under construction may not be the same BMP that should be utilized for post-construction management. It may not be reasonable for any number of factors including: the size of the site, other support practices in place that reduce erosion, and easement restrictions, for a large pond to be in place once a site has mostly permanent cover.

The cover management system implemented on a site significantly impacts the amounts of erosion and sediment yield on a site. Large amounts of sediment are eroded while a site have bare soil. As a site is seeded with permanent cover, the soil erosion and yield on the site may be almost non-existent. At times, the bare-soil erosion and sediment yield may be 10,000 times higher than that for a permanent cover. BMP longevity varies greatly depending on the sediment load entering the BMP, which is based on the cover management practice, among other things. For a bare-soil construction site, it is possible to have an appropriately sized BMP fill with sediment within a year. With the same BMP and site after the soil has been stabilized with permanent grass cover, the BMP may perform for decades, or even the design 
life of the site. It is very important to stabilize a site as soon as possible to reduce the erosion of the site, and increase the longevity of the BMP.

\section{REFERENCES}

[1] Douglass, Swift and Burns., (Douglass 1974; Swift 1985; Swift and Burns 1999).. Communities, and the Environment::College of Agriculture,

[2] ERA., (2013)-Ethiopia Road Authority, pavement rehabilitation and asphalt overlay design manual, Addis Ababa, Ethiopia

[3] American Association of State Highway and Transportation Officials. (2002). Guide for Design of Pavement Structures. Washington, D.C. 2001.

[4] EPA.Water, (June 1, 2014). Clean Water Act of 1972 Best Management Practices: Check Dams..:United States. EPA.Water: U.S. 2014..

[5] Fifield, J., 2004.. Designing for effective sediment and erosion control on construction sites, :Forester Communications, Santa Barbara, CA,.

[6] Fifield, J., 2010.. Guideline for erosion and sediment control in Malaysia.., Department of Irrigation and Drainage. .

[7] Hedau, A. L. \& Sanghai, S. S., 2014. Data Collection Techniques for Activity Based Trip Generation Modeling. Proceedings of 3rd International Conference on Quality Up gradation in Engineering, Science \& Technology, IC-QUEST 2014, , 19 April

[8] kell., 1938. soil erosion and sedimentation..

[9] Pamela J. Edwards, Frederica Wood, and Robin L.P, 1995.. Effectiveness of Best Management Practices.. Washington: United States Department of Agriculture.

[10] Navya S V., S. Sanjay Kumar, Gymmy Joseph Kattoor, 2013. Trip Generation Model for the Core Area of Thiruvananthapuram City. International Journal of Innovative Research in Science, Engineering and Technology, 2(1), pp. 99-106.

[11] Paterson, W.D.O. (1987). Models for Planning and Management." Road Deterioration and Maintenance Effects". Frist Edition. Washington, D.C: World Bank.

[12] Price J.C., and Karesh.R, 2000. soil erosion, sedimentation and flooding overcoming in forest management and preservation. Manual. Washington: United States Department of Agriculture.

[13] Scienjo, K., 2015.. “The Agronomy Guide. .. s.1.:Penn State College of Agricultural..

[14] White, P and Hunt, D, 2001. conservation of soil and water.:American department of agriculture, 
AUTHORS PROFILE

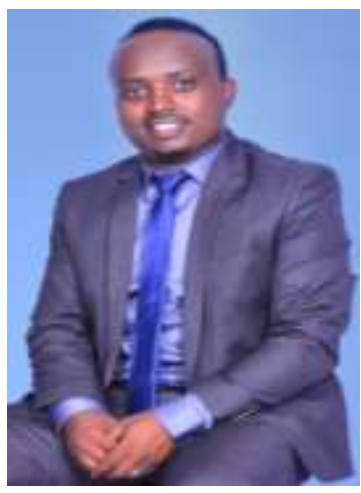

Engineer. Dagimwork Asele Manuka is working as Lecturer in Department of Civil Engineering, College of Engineering, at Wolaita Sodo University, Ethiopia. Dagimwork has enquired Bachelor of Science (B.Sc.) Degree in Civil Engineering in the year 2014 and Master of Science (M.Sc.) Degree in Road and Transport Engineering in 2019. During, Bachelor study he has persevered Distinction rank and his thesis work by the title: "Comparative study of Rigid and Flexible Pavement in Ethiopia" with "Excellent" rating from Hawassa University, Institute of Technology (IOT). Again, Great Distinction rank in Master of Science (M.Sc.) and his thesis work is by the title "Analysis on Traffic Flow Characteristics in Two-way Two-Lane Road under Mixed Traffic Condition" with "Very Good" rating from Arba Minch University (PostGraduate program), Ethiopia. Mr. Dagimwork is Member of Wolaita Sodo University Teachers Association (WSUTA) and Ethiopia Association of Civil Engineers (EACE). His research interest's area is: traffic and transportation modelling, Performance appraisal of midblock and 
intersections, Pavement design and analysis, flow characteristics and analysis, transport system management (TSM), Highway maintenance and drainage design and modelling, software analysis adopting HDM, Sidra intersection Eagle point road design software's. Contributions: in training, filed effort accomplishments and laboratory analysis and have more than 12 publication paper in various international journal indexing. 